\title{
Sardine Scales: A Promising Source of Marine Biomaterials
}

\author{
Fatima Zahra Aboudamia ${ }^{1,2 *}$, Fadna Aatab ${ }^{1}$, Abderrahim Jaouad ${ }^{2}$, Mohamed Bouchdoug ${ }^{2}$, Mariem \\ Kharroubi $^{1}$
}

1. Laboratory of Biotechnologies, Specialized Center of Valorization and Technology of Sea Products, National Institute of Fisheries Research (INRH), Agadir, Morocco

2. Research Team of Innovation and Sustainable Development \& Expertise in Green Chemistry, "ERIDDECV", Department of Chemistry, Faculty of science, Cadi Ayyad University, Marrakesh, Morocco

* Correspondence: aboudamia.fatimazahra@gmail.com;

Scopus Author ID 57216953825

Received: 4.09.2021; Revised: 12.10.2021; Accepted: 16.10.2021; Published: 26.10.2021

\begin{abstract}
The current paper highlighted the physicochemical characteristics of sardine scales (S.pilchardus), which are considered hitherto as solid marine litter despite their richness on biomaterials of high added value. The collected fish scales were washed thoroughly, dried, and grounded into a powder. The prepared samples were characterized using infrared spectroscopy (FT-IR), x-ray diffraction (XRD), scanning electron microscopy coupled with electron dispersive spectroscopy (SEM/EDS). The findings of (FT-IR); (XRD); and (EDS) show that sardine scales contain both organic and inorganic phases. The (SEM) analysis has revealed that sardine scales have a porous and fibrous structure. The physicochemical results confirm that S.pilchardus scales are a pioneering source of marine biomaterials.
\end{abstract}

Keywords: fish by-products; fish scales; marine biomaterials; S.pilchardus; solid marine litter.

(C) 2021 by the authors. This article is an open-access article distributed under the terms and conditions of the Creative Commons Attribution (CC BY) license (https://creativecommons.org/licenses/by/4.0/).

\section{Introduction}

In worldwide, the high consumption of fish is growing day after day because of its benefits on human health. In parallel with this excessive consumption, a significant increase in marine by-products is observed in fishing areas. For example, fish filleting, salting, and smoking produce an enormous amount of by-products (50-75\% of processed fish), with a total of 3.17 million tons/year [1]. The fish canning industry is considered the second source of byproducts (30-65\% of processed fish), with a total of 1.5 million tons/year [1]. In Morocco, the processing companies of fishery products occupy a privileged place in the national economy. It processes nearly $70 \%$ of coastal fishing catches and exports about $85 \%$ of its production over hundreds of countries in the five continents. Furthermore, Sardina .pilchardus is one of the most important commercial pelagic fish species. The annual sardine processing industries generate a considerable amount of waste such as viscera, bones, heads, tails, etc scales considered as marine by-products. Figure 1 summarizes the different by-products obtained from common sardine (S.pilchardus). 


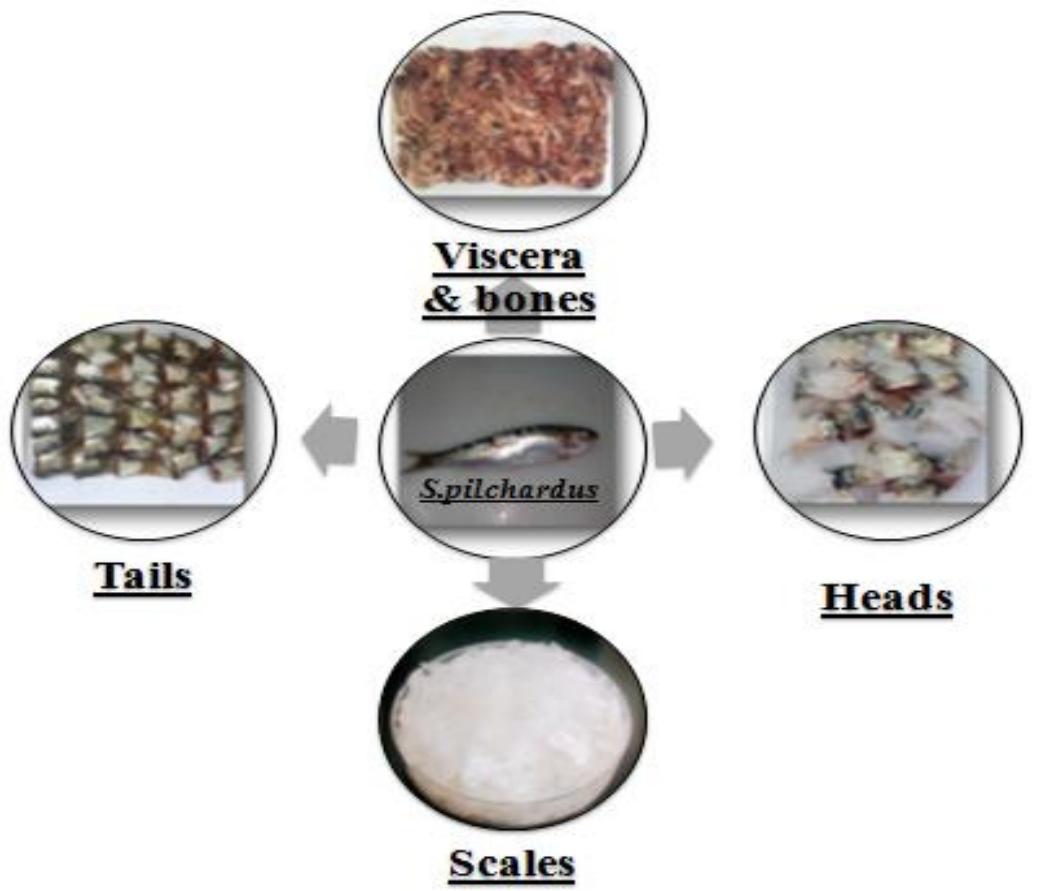

Figure 1. Sardina pilchardus by-products.

In worldwide and during the last twenty years, marine processing industries have realized that the residues generated by their activities, which were then synonymous to costs, could be kept at food grade to become a by-product, that is to say, the raw material of a downstream activity [2]. To ensure the sustainability of fishing, increase the profitability of the sector's activities, and resolve the management of marine by-products, it has become essential to improve their added value. Therefore, the heading is mandatory to recover fish by-products after each processing operation, such as filleting and evisceration. The marine by-product processing sector is virtually absent at the national level, despite the richness and diversity of fishing products. Furthermore, the valuation routes for marine by-products are limited to fishmeal production [3] and oil [4]. However, these two activities require a lot of energy and deplete natural resources with low quality of the final product. Faced with this state of affairs, a new avenue for valuing marine by-products should be explored; their objectives are to mitigate or eliminate the harmful impact of fishery by-products on the environment, increase profitability and maximize corporate profit. As sardine scales correspond to 2-3\% in the whole species, it's necessary to highlight their importance, especially that this marine matrix is characterized with important mechanical properties and structural configurations [5] that's why they are the object of several studies in the last decade [6-10]. Among the bio-innovative solutions reported to evaluate sardine scales (S.pilchardus), those of the extraction of biomaterials as collagen [11], gelatin [12], chitin [13], chitosan [14], and hydroxyapatites [15]. These marine compounds might apply in various fields, including agricultural, food, cosmetic, nutraceutical, and pharmaceutical. To the best of our knowledge, no study has evoked the physicochemical characterization of S.pilchardus scales caught on the Moroccan littoral. The aim of the current paper is to shed light on the interest of the recovery of sardine scales (S.pilchardus) available in abundance as a discarded marine litter from sardine companies. It characterizes their properties based on IR spectroscopy (FTIR), x-ray diffraction (XRD), scanning electron microscopy coupled with electron dispersive spectroscopy (SEM/EDS). 


\section{Materials and Methods}

\subsection{Materials.}

Fish scales used in this study were isolated from fresh common sardine (S.pilchardus) coughed in the sea of Agadir - Morocco. The raw material was washed thoroughly with tap water to remove adhering dust and soluble impurities from their surface, dried in the oven at $40^{\circ} \mathrm{C}$ for $48 \mathrm{~h}$ till the sardine scales became crispy. The dried fish scales were grounded into a fine powder (SSP) using a mechanical grinder (MASSCOLOIDER, Motor: 11Kw, 4P, made in Japan). The obtained powder was sieved using a hand sieve with a 280 -micron mesh range.

\subsubsection{Characterization of sardine scales powder (SSP).}

The prepared (SSP) functional groups were measured using Fourier Transform Infrared Spectroscopy (FTIR, Vertex 70 series) operated at $4 \mathrm{~cm}^{-1}$ over a range of $4000-400 \mathrm{~cm}^{-1}$. Surface morphology of (SSP) was conducted using (SEM, Tescan, Vega 3) operated at 10kV. The elemental composition of (SSP) was determined using Energy-dispersive spectroscopy (EDS). The crystallinity index of (SSP) was analyzed using X-ray diffraction (XRD) (Smart Lab X-ray diffractometer); the measurement was in the scanning range between $2 \theta$ angles of 5 to 90 .

\section{Results and Discussion}

\subsection{Electron Dispersive Energy $x$-Ray (EDS).}

Sardine scales are intended for analysis by EDS; according to the typical EDS graphs depicted in Figure 2 already mentioned in earlier work [14], we observe that this raw material is formed of organic and inorganic parts. The organic part is made up of the following elements: $\mathrm{C}(17.68 \%), \mathrm{O}(31.11 \%)$, and $\mathrm{N}(7.45 \%)$. In addition, the inorganic part is made up of a set of mineral elements with different amounts such as: $\mathrm{Ca}(31.9 \%), \mathrm{P}(11.18 \%), \mathrm{S}(0.35 \%), \mathrm{Mg}$ (0.14\%), $\mathrm{Al}(0.07 \%), \mathrm{Na}(0.03 \%), \mathrm{Si}(0.09 \%)$.

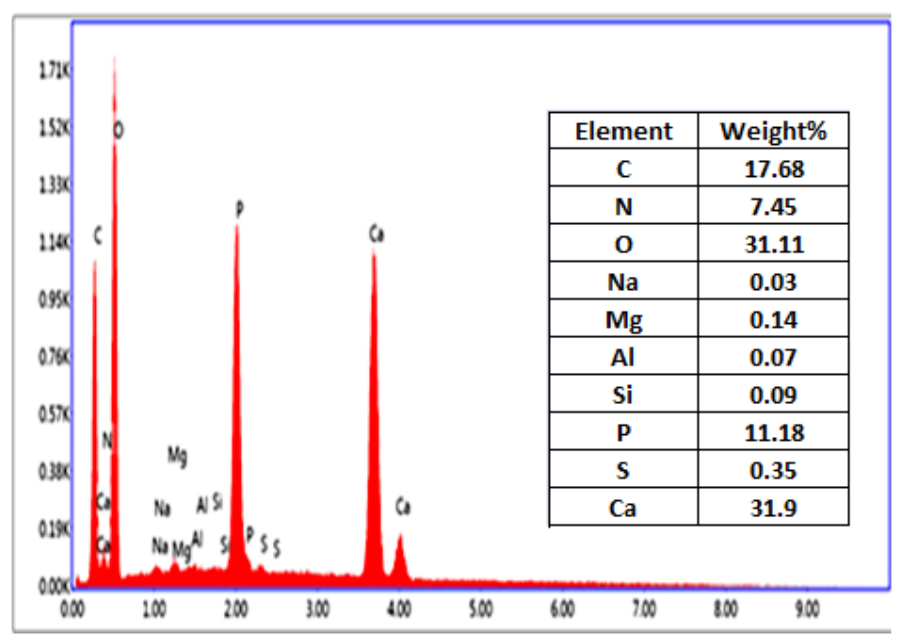

Figure 2. EDS spectra of (SSP).

Consequently, and according to the findings of EDS analysis, the mineral part in the sardine scales is about $43.76 \%$, and the organic part represents a mass content of $56.24 \%$. The results obtained from the EDS spectra shown in Figure 2 are in agreement with that of [1214,16], who reported that the fish scale is a promoter source of chitin, chitosan, gelatin, 
collagen, and hydroxyapatites [15] given its richness in organic and inorganic matter. Furthermore, the presence of some atoms in sardine scales like $\mathrm{Na}, \mathrm{Mg}, \mathrm{Al}, \mathrm{Si}$, and $\mathrm{S}$ in low content could be explained to environmental pollution of fish habitat.

\subsection{Scanning Electron Microscopy (SEM).}

Figure 3 shows SEM micrographs of (SSP) according to two magnifications: (a): $5 \mu \mathrm{m}$, (b): $20 \mu \mathrm{m}$. The observation of the SEM micrographs of the (SSP) reveals that the sardine scales are transformed after grinding into materials of a fibrous and filamentous nature.

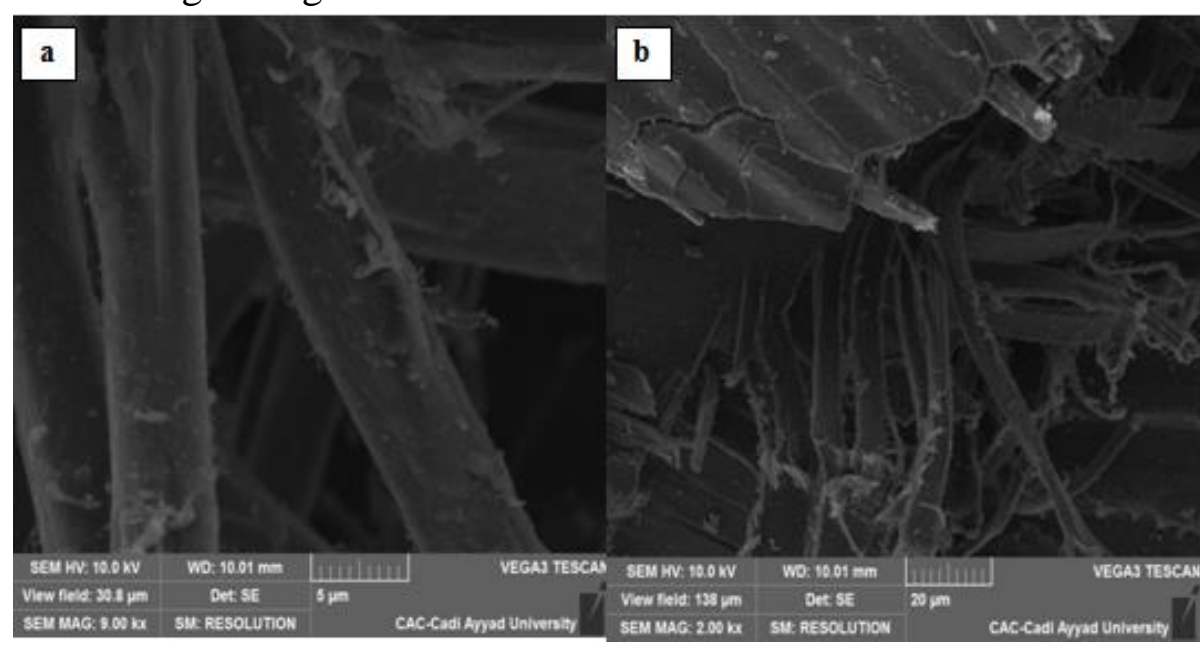

Figure 3. SEM micrographs of (SSP).

This dense and filamentous network could be explained by the existence of inorganic and organic compounds in the (SSP). The obtained results are in agreement with those of $\mathrm{Wu}$ et al. in [17].

\subsection{Fourier Transform- Infrared (FT-IR) Spectroscopy.}

Spectra of (SSP) are shown in Figure 4. The FT-IR analysis of (SSP) depicted amino, carboxylic, phosphate, and carbonyl groups. The peak around $3429 \mathrm{~cm}^{-1}$ is attributed to the $\mathrm{OH}$ group stretch vibration of adsorbed water [18]. The band at $2912 \mathrm{~cm}^{-1}$ corresponds to the asymmetric elongation vibration for $\mathrm{CH}_{2}$ [19]. The band at $1637 \mathrm{~cm}^{-1}$ corresponds to a bending vibration of the amide $\mathrm{NH}$, attributed to type I collagen.

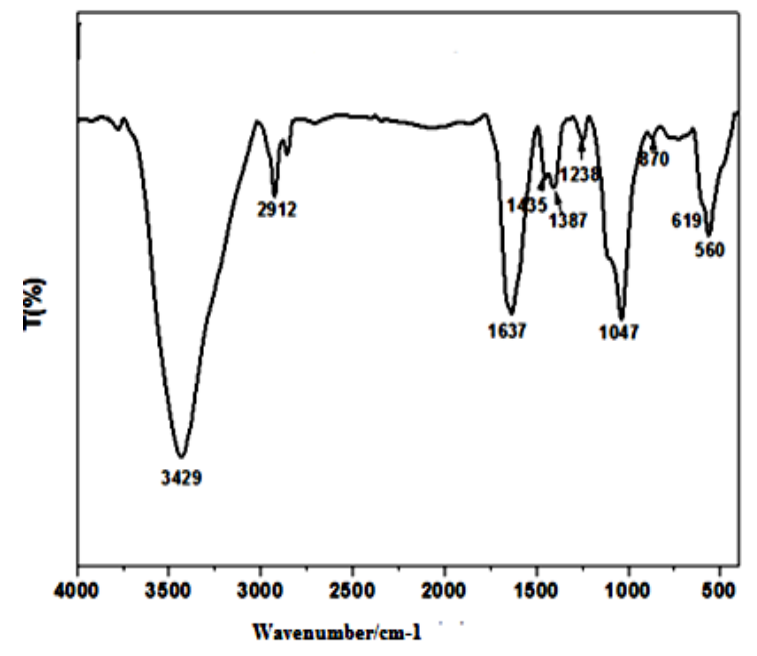

Figure 4. FT-IR spectra of (SSP). 
The carbonate group $\left(\mathrm{CO}_{3}{ }^{2-}\right)$ in the FTIR spectrum is identified by strong bands at $870 \mathrm{~cm}^{-1}$ and at $1435 \mathrm{~cm}^{-1}$ associated respectively with the out-of-plane bending mode and the asymmetric stretching of carbonate anions [20]. The band at $1238 \mathrm{~cm}^{-1}$ corresponds to a bending vibration of $\mathrm{NH}$ amide III, attributed to type I collagen. The bands at $1047 \mathrm{~cm}-{ }^{1}$, $619 \mathrm{~cm}^{-1}$, and $560 \mathrm{~cm}^{-1}$ indicate asymmetric stretching and vibrations symmetrical and asymmetrical bending of the phosphate group $\left(\mathrm{PO}_{4}{ }^{3-}\right)$ in (SSP) spectra. The results found by this analysis are similar to the scientific literature [21-24].

\subsection{X-ray Powder Diffractometry (XRD) Analysis.}

XRD analysis was used to detect the phase composition of (SSP); Figure 5 illustrates the analysis (SSP) by X-ray diffraction (XRD). It is clear that (SSP) has two phases: a crystalline phase and an amorphous phase. Small peaks are mentioned in the $2 \theta$ values of $11^{\circ}$, $16^{\circ}, 20^{\circ}, 23^{\circ}$, and $25^{\circ}$. In addition, very visible peaks are observed at $2 \theta$ of $25^{\circ}, 28^{\circ}, 32^{\circ}$, $40^{\circ}, 47^{\circ}, 50^{\circ}, 54^{\circ}$.

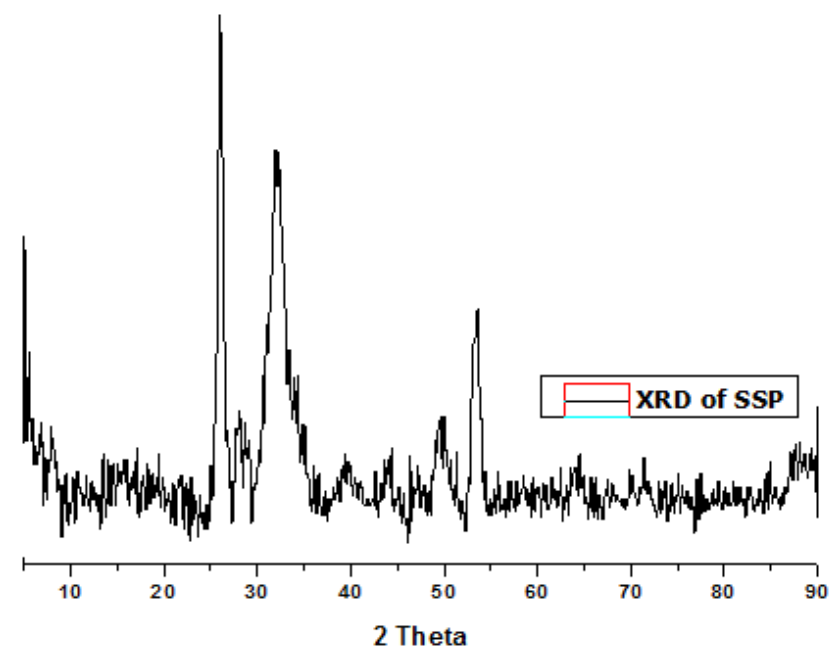

Figure 5. XRD of (SSP).

The small peak observed in the $2 \theta$ value of $20^{\circ}$ corresponds to the existence of chitin and proteins, in particular type I collagen, in the (SSP) $[19,25,26]$. The peak observed between the $2 \theta$ range of $32^{\circ}$ is an indicator of the existence of the complex of $\left[\mathrm{Ca}_{10}\left(\mathrm{PO}_{4}\right)_{6}(\mathrm{OH})_{2}\right]$ the chemical band to the mineral component of the bones and hard tissue of animals $[15,18,27,28]$. During this work, the XRD analysis is in line with the results previously found in the Fourier transform analysis (FT-IR) and those of the scanning electron microscope and those of the elemental analysis by EDS (SEM / EDS).

\section{Conclusions}

The present paper showed that sardine scales (S.pilchardus) as fish waste are a pioneering source of marine biomaterials as hydroxyapatites, gelatin, collagen, chitin, and chitosan. Moreover, the physicochemical characterization of sardine scales powder (SSP) based on FT-IR, XRD, SEM /EDS shows its richness on organic and inorganic compounds with a porous and fibrous structure. These results open up new avenues in the recovery of fish by-products. It could be an important stream that ensures sustainable fishing and improves the profitability of the sector activities. Furthermore, this paper research will offer a great opportunity to scientists and industrials to use sardine scales in the next years as an alternative 
raw material to extract renewable products to decrease environmental pollution and increase economic incomes.

\section{Funding}

This research received no external funding.

\section{Acknowledgments}

This research has no acknowledgment.

\section{Conflicts of Interest}

The authors declare no conflict of interest.

\section{References}

1. Lopes, C.; Antelo, L.T.; Franco-Uría, A.; Alonso, A.A.; Pérez-Martín, R. Valorisation of fish by-products against waste management treatments - Comparison of environmental impacts. Waste Manag. 2015, 46, 103112, https://doi.org/10.1016/j.wasman.2015.08.017.

2. Le Floc'h, P.; Bourseau, P.; Daurès, F.; Guérard, F.; Le Grel, L.; Meunier, M.; Tuncel, M. Valorisation des coproduits de la mer et territoire : enjeux territoriaux. Rev. d'Économie Régionale Urbaine 2011, février, 213, https://doi.org/10.3917/reru.111.0213.

3. Mih, H.; Lacherai, A. Nutritional Properties of Fish Meal Produced from Fresh By-Products of Sardina pilchardus. J. Fish. Environ. 2020, 44, 16-23.

4. Mkadem, H.; Kaanane, A. Recovery and characterization of fish oil from by-products of sardine (Sardina pilchardus) in the canning process. J. Aquat. Food Prod. Technol. 2019, 28, 1037-1050.

5. Yaseen, A.A.; Waqar, T.; Khan, M.A.A.; Asad, M.; Djavanroodi, F. Fish Scales and Their Biomimetic Applications. Front. Mater. 2021, 8, 114.

6. Ji, Q.; Li, H.; Zhang, J. Preparation and characterization of bio-based activated carbon from fish scales. BioResources 2020, 16, 614-621, https://doi.org/10.15376/biores.16.1.614-621.

7. Gune, R.; Sawant, A.; Joglekar, N. Formation of Bio-Based Polymer (Poly-Lactic Acid) From Potato Peel Waste and Blending with Chitosan Extracted from Fish Scales. Int. J. Res. Eng. Sci. Manag. 2021, 4, $13-18$.

8. Yogeshwaran, S.; Natrayan, L.; Rajaraman, S.; Parthasarathi, S.; Nestro, S. Experimental investigation on mechanical properties of Epoxy/graphene/fish scale and fermented spinach hybrid bio composite by hand lay-up technique. Mater. Today Proc. 2021, 37, 1578-1583.

9. Rui, C.E.; Navaneethan, K. Organic Solvent Nanofiltration Using Fish-Scale-Derived Membrane. In IRCSET 2020; Springer, 2021, 267-280.

10. Rafael, M.Y.; Rafael, R.; Landingin, E.; Rafael, R.; Tayag, G.; Santos, J.P.; Rafael, M.J. Gelatin from Milkfish Scales for Food Application. CLSU Int. J. Sci. Technol. 2021, 5, 47-59.

11. Bellali, F.; Kharroubi, M.; Lahlou, F.Z.; Lotfi, M.; Radi, Y.; Bourhim, N. Response surface methodology optimization of deproteinization from sardine (Sardina pilchardus) scale of moroccan coast. Int. J. Biotechnol. 2013, 2, 182-192.

12. Harada, O.; Kuwata, M.; Yamamoto, T. Extraction of gelatin from sardine scales by pressurized hot water. Nippon Shokuhin Kagaku Kogaku Kaishi 2007, 54, 261-265, https://doi.org/10.3136/nskkk.54.261.

13. Zahra, F.; Kharroubi, M.; Neffa, M.; Jaouad, A. Extraction and characterization of ß- chitin from sardine' s scales Sardina pilchardus (Walbaum, 1792) 2020, 1, 293-303.

14. Aboudamia, F.Z.; Kharroubi, M.; Neffa, M.; Aatab, F.; Hanoune, S.; Bouchdoug, M.; Jaouad, A. Potential of discarded sardine scales (Sardina pilchardus) as chitosan sources. J. Air Waste Manag. Assoc. 2020, 00, https://doi.org/10.1080/10962247.2020.1813840.

15. Piccirillo, C.; Pullar, R.C.; Tobaldi, D.M.; Castro, P.M.L.; Pintado, M.M.E. Hydroxyapatite and chloroapatite derived from sardine by-products. Ceram. Int. 2014, 40, 13231-13240.

16. Piccirillo, C.; Pullar, R.C.; Costa, E.; Santos-Silva, A.; Pintado, M.M.E.; Castro, P.M.L. Hydroxyapatitebased materials of marine origin: A bioactivity and sintering study. Mater. Sci. Eng. C 2015, 51, 309-315.

17. Wu, W.; Zhou, Z.; Sun, G.; Liu, Y.; Zhang, A.; Chen, X. Construction and characterization of degradable fish scales for enhancing cellular adhesion and potential using as tissue engineering scaffolds. Mater. Sci. Eng. C 2021, 122, 111919, https://doi.org/10.1016/j.msec.2021.111919.

18. Muhammad, N.; Gao, Y.; Iqbal, F.; Ahmad, P.; Ge, R.; Nishan, U.; Rahim, A.; Gonfa, G.; Ullah, Z. Extraction of biocompatible hydroxyapatite from fish scales using novel approach of ionic liquid pretreatment. Sep. Purif. Technol. 2016, 161, 129-135, https://doi.org/10.1016/j.seppur.2016.01.047. 
19. Kumari, S.; Annamareddy, S.H.K.; Abanti, S.; Rath, P.K. Physicochemical properties and characterization of chitosan synthesized from fish scales, crab and shrimp shells. Int. J. Biol. Macromol. 2017, 104, 16971705.

20. Torres, F.G.; Troncoso, O.P.; Nakamatsu, J.; Grande, C.J.; Gómez, C.M. Characterization of the nanocomposite laminate structure occurring in fish scales from Arapaima Gigas. Mater. Sci. Eng. C 2008, 28, 1276-1283, https://doi.org/10.1016/j.msec.2007.12.001.

21. Ali, A.M.M.; Benjakul, S.; Prodpran, T.; Kishimura, H. Extraction and characterisation of collagen from the skin of golden carp (Probarbus Jullieni), a processing by-product. Waste and biomass valorization 2018, 9 , 783-791.

22. Huang, Y.C.; Hsiao, P.C.; Chai, H.J. Hydroxyapatite extracted from fish scale: Effects on MG63 osteoblastlike cells. Ceram. Int. 2011, 37, 1825-1831, https://doi.org/10.1016/j.ceramint.2011.01.018.

23. Nadeem, R.; Ansari, T.M.; Khalid, A.M. Fourier Transform Infrared Spectroscopic characterization and optimization of $\mathrm{Pb}(\mathrm{II})$ biosorption by fish (Labeo rohita) scales. J. Hazard. Mater. 2008, 156, 64-73, https://doi.org/10.1016/j.jhazmat.2007.11.124.

24. Liu, Y.; Liu, M.; Ji, S.; Zhang, L.; Cao, W.; Wang, H.; Wang, S. Preparation and application of hydroxyapatite extracted from fish scale waste using deep eutectic solvents. Ceram. Int. 2021, 47, 9366-9372, https://doi.org/10.1016/j.ceramint.2020.12.067.

25. Bahrololoom, M.E.; Javidi, M.; Javadpour, S.; Ma, J. Characterisation of natural hydroxyapatite extracted from bovine cortical bone ash. J. Ceram. Process. Res. 2009, 10, 129-138.

26. Paul, S.; Pal, A.; Choudhury, A.R.; Bodhak, S.; Balla, V.K.; Sinha, A.; Das, M. Effect of trace elements on the sintering effect of fish scale derived hydroxyapatite and its bioactivity. Ceram. Int. 2017, 43, 1567815684, https://doi.org/10.1016/j.ceramint.2017.08.127.

27. Liu, D.M.; Yang, Q.; Troczynski, T.; Tseng, W.J. Structural evolution of sol-gel-derived hydroxyapatite. Biomaterials 2002, 23, 1679-1687, https://doi.org/10.1016/S0142-9612(01)00295-2.

28. Saenz, N. Obtención De Material Colagenoso De Escamas De Pescado Y Su Esterilización Con Radiación Gamma. 